\title{
Das atmosferas, acasos e turbulências
}

Maria Cristina Franco Ferraz

Recebido em 15/07/2011 - Aprovado em 15/09/2011

\begin{abstract}
Resumo
O artigo explora alguns aspectos da cultura "somática" contemporânea, expressos de modo significativo na literatura anglo-saxônica recente. Para tal, analisa o romance Atmospheric Disturbances, de Rivka Galchen, editado em 2008. A crescente ênfase cultural e midiática no plano material do corpo-em especial nas redes neuronais do cérebro, em hormônios e genes -, acionada para se dar conta de todas as esferas da experiência humana, fornece roteiros de subjetivação de cunho biologizante. Novas sindromes descritas e catalogadas de modo proliferante tendem a medicalizar e a domesticar estranhamentos e ambiguidades elaborados há séculos, sob outras claves, pela cultura letrada ocidental (da literatura à psicanálise). A leitura crítica do romance de Galchen permite ressaltar questões éticas, políticas e filosóficas implicadas no processo de naturalização e de progressiva desespiritualização do fenômeno humano, presente na cultura contemporânea.
\end{abstract}

Palavras-chave: cultura somática; literatura anglo-saxônica; subjetividade contemporânea. 
A literatura anglo-saxônica recente nos fornece alguns exemplos significativos de certa inflexão observada na cultura contemporânea, identificada com a expressão "cultura somática". De modo geral, trata-se da tendência crescente à redução da experiência humana em sua totalidade (pensamento, religiosidade, sentimerntos, ética etc) à materialidade de um corpo cientificamente objetivado, com ênfase no cérebro, nos hormônios e nos genes. Essa tendência biologizante na configuração do que somos tem-se manifestado em ficções anglo-saxônicas contemporâneas, configurando o que Mark Roth, em breve ensaio, denominou de "Rise of the Neuronovel". 1

Sem querer entrar no mérito da pertinência ou não deste termo, pode-se observar de fato que novos roteiros de subjetivação, apoiados no privilégio do plano biológico, sobretudo neurológico, vêm se introduzindo em ficções e na esfera cultural (sites, blogs), sob o modo do que alguns autores chamam de bioidentidades, neuroselves ou individualidades somáticas (cf. ROSE). Nesses produtos culturais, as narrativas de si e os personagens se configuram a partir de rubricas patológicas, tais como as síndromes de Huntington, de Asperger, Tourette, Capgras etc. Emergem também, por vezes, como perspectivas outras, como alternativas aos padrões de normalidade, pleiteando o estatuto de subculturas, como diferenças a serem despatologizadas e integradas como potencialmente enriquecedoras (e não a serem "curadas"). Essa afirmação de si como alteridade já implica, obviamente, uma adesão ao novo quadro classificatório, sua inscrição no regime de certos distúrbios ou disfunções codificados nas últimas décadas.

O livro em questão se intitula Atmospheric Disturbances (Distúrbios atmosféricos), romance de estreia da jovem autora canadense, atualmente residente em Nova York, Rivka Galchen, que possui dupla formação universitária: em Letras e em Medicina, com especialidade em Psiquiatria. Os pais da autora, emigrados de Israel, se inscrevem na obra. De modo mais direto, seu pai, Tzvi Gal-Chen, professor universitário de meteorologia, torna-se efetivamente um personagem espectral do enredo. Como que em linha d'água, a mãe da autora paira também sobre a obra, por seu trabalho como programadora computacional do Laboratório Nacional de Graves Tormentas (National Severe Storms Laboratory), instituição cujo nome sugestivo convoca e aglutina as forças do imaginário, bem como o desejo de controle, de previsão das imparáveis oscilações e das variações constantes da atmosfera terrestre.

Eis, de modo sucinto, o enredo. O psiquiatra e psicanalista

Cf. Mark Roth, "The Rise of Neuronovel", $\mathrm{n}+1,14 / 09 / 2009$, disponível em http://nplusonemag.com/rise-neuronovel nova-iorquino Leo Liebenstein, ao ver um belo dia sua mulher (Rema) entrar em casa trazendo um novo cãozinho, não a reconhece, tomando-a a partir de então por um simulacro, por uma impostora, uma réplica, uma Ersatz-Rema. Em paralelo, Dr. Leo 
Liebenstein está tratando de um paciente paranóico chamado Harvey - nome que, por sinal, lembra o famoso cometa Halley. Harvey pensa ser um agente secreto da fictícia Royal Academy of Meteorology incumbido da tarefa de antever e de deter cataclismas meteorológicos iminentes. Está assim constantemente colocando sua vida em risco, pois viaja, desaparece sem dar notícia, seguindo supostas instruções e mensagens entrelidas em jornais e em previsões meteorológicas televisivas.

Para obter sucesso no tratamento (um sucesso derrisório, meramente pragmático), Dr. Leo implementa uma tática totalmente herética sugerida por sua mulher: durante as sessões, Rema liga para o marido, fazendo-se passar por um superior da (falsa) academia meteorológica, para transmitir a Harvey supostas missões a serem realizadas bem perto de casa, no próprio bairro. Impediria, assim, seus sumiços. Embora o médico inicialmente resista ao uso dessa estratégia, acaba aplicando-a. Tem então início a proliferação em abismo de simulacros, um vertiginoso jogo de indecidibilidade entre os personagens e seus duplos.

Agravando o caso, o estratagema ficcional sugerido por Rema introduz elementos do real que extrapolam o próprio romance: ela se faz passar por um superior da pseudo academia meteorológica chamado Tzvi Gal-Chen, nome verdadeiro do pai da autora, que se dedicara de fato profissionalmente a lidar com imprevisíveis fenômenos meteorológicos. Após um breve período de sucesso desse expediente nada ortodoxo, o paranóico Harvey acaba mesmo assim desaparecendo do mapa. Paralelamente, Dr. Leo sai em busca da "verdadeira" Rema, partindo, ele também, sem deixar qualquer aviso para Buenos Aires, cidade onde sua mulher tinha nascido e sido criada.

O tema político dos "desaparecidos", em sua forte presença na Argentina, intervém explicitamente na trama, com no mínimo dois efeitos. Por um lado, aponta para o esvaziamento da ética e da política que acompanha a incorporação dessas novas categorizações e crenças biopolíticas, uma vez que o desaparecimento deixa de se inscrever no campo das lutas e ações humanas, restringindo-se ao regime da "vida nua" (Agamben) próprio às individualidades somáticas ou neuroselves.

Na trama, essa perda ético-política é ainda reforçada por um gesto cínico que tem por efeito colocar sob suspeita a própria facticidade desses crimes políticos, contaminando o tema do "desaparecimento" político com o terreno pantanoso da indecibilidade entre meras versões. Eis como isso se dá no romance de Galchen: indo ao encontro de sua sogra argentina, Leo descobre que o pai de Rema teria sido um dos "desaparecidos" da ditadura. No entanto, um pouco adiante, essa versão é contrariada pela própria Rema, que afirma que seu pai teria banalmente abandonado sua mãe. Rema comenta que, contrabandeando a 
dor de perda e abandono por algo mais honroso, sua mãe teria integrado essa ficção, não passando, portanto, de uma mentirosa.

Diversos jogos do falso são explorados no romance, sempre balizados pela moldura somática. Não apenas no sentido central da trama - a busca quixotesca, necessariamente fadada ao fracasso, pela "verdadeira" Rema -, mas em diversos detalhes que assinalam o campo deslizante do simulacro e a perda de qualquer referência em que se possa ancorar barcos bêbados. Por exemplo, a chegada do nova-iorquino à Argentina parece de início restituir às coisas seu sabor genuíno: Leo toma uma bebida que, segundo ele, tinha realmente sabor de maçã, e não de essência de maçã sintetizada (GALCHEN, 2008, p. 91). Entretanto, essa promessa de restituição de um mundo real e verdadeiro no extremo sul das Américas logo se revela, como veremos, um logro total. ${ }^{2}$

Partindo para a inóspita Patagônia - onde, com pseudônimo, o Dr. Leo Liebenstein aceitara um trabalho como (falso) meteorologista -, em um movimento de descentramento ainda mais radical, o psiquiatra observa que há em seu quarto de hotel um arremedo de lareira, acesa a gás, com esculturas de madeira que nunca se queimam (Idem, p. 165). Em um vilarejo onde foi parar depara-se ainda com falsos gaúchos que oferecem, a preços módicos, tours turísticos a cavalo (Idem, p. 167). Esses detalhes contribuem para colocar em derrisão a crença no inconsciente (longínqua e borgeana Patagônia) como último recurso e sítio de nossa suposta natureza mais autêntica, primordial.

Conforme se lê no romance, segundo Rema a Patagônia é "o selvagem e incultivado inconsciente da Argentina". Para o psiquiatra em crise, no entanto, mais parece um inconsciente feito de Lego, inodoro, insípido ("it was a[n...] unscented Lego-land of an unconscious", Ibidem). Encontram-se então barrados tanto o mito patagônico quanto a possibilidade do reencontro com o "verdadeiro", com o suposto "original" perdido nesse mundo-Lego, radicalmente fake. Inevitável lembrar aqui a bastante citada observação de Zizek acerca do nosso café sem cafeína, do sexo sem sexo, da guerra sem guerra. Neste mundo fake, em que circulam rótulos aplanadores (como no caso da proliferação crescente de novas síndromes e disfunções), Leo insiste quixotescamente em encontrar sua verdadeira Rema.

Inserido em um regime de sentido biopoliticamente confi-

2 Inevitável mencionar aqui Borges e sua visão do Sul, referência implícita desta passagem.

3 “I didn't actually believe a word of what I said. Even if I did, briefly, that would have been purely on account of my distorting neurologic state." (p. 230, grifo meu). gurado, Leo Liebenstein parece por vezes transbordar a moldura patológica que domestica sua experiência ao referi-la unicamente a um distúrbio neurológico objetivamente assinalável. Evidentemente, no romance sua doença enquadra e aprisiona a potência ontológica de sua experiência singular, na medida em que é de saída sugerida (já por sua profissão) e explicitamente reafirmada na trama, sobretudo no desfecho do livro. ${ }^{3}$ Em outras passagens, essa neuroperspectiva se inscreve de modo mais amplo, sob a ru- 
brica das "síndromes de misidentification, de falsa-identificação" (GALCHEN, 2008, p. 207). Entretanto, de modo ambíguo, as percepções distorcidas, as variações atmosféricas que Leo sofre e flagra também se desdobram no livro em um horizonte carregadamente ontológico ancorado em outras matrizes culturais, especialmente na densa tradição literária (introduzida também na psicanálise) do tema dos duplos, da figura desconcertante e inquietante do Doppelgänger.

A ambiguidade instala-se no romance. Enquanto a nova

4 "Delusional misidentification syndrome is an umbrella term, introduced by Christodoulou (book "The Delusional Misidentification Syndromes", Karger, Basel,1986) for a group of delusional disorders that occur in the context of mental or neurological illness. They all involve a belief that the identity of a person, object or place has somehow changed or has been altered. As these delusions typically only concern one particular topic they also fall under the category called monothematic delusions.

This syndrome is usually considered to include four main variants:

- The Capgras delusion is the belief that (usually) a close relative or spouse has been replaced by an identical-looking impostor.

- The Fregoli delusion is the belief that various people the believer meets are actually the same person in disguise.

- Intermetamorphosis is the belief that people in the environment swap identities with each other whilst maintaining the same appearance.

- Subjective doubles, described by Christodoulou in 1978 (American Journal of Psychiatry $135,249,1978$ ) in which a person believes there is a doppelgänger or double of him or herself carrying out independent"

Cf. http://en.wikipedia. org/wiki/Delusional_ misidentification_syndrome. moldura cultural - a cultura somática - a que ele adere orienta fortemente tanto a produção quanto a recepção da obra, o recurso a outra matriz cultural, em que a experiência não se patologiza biopoliticamente mas se desdobra em um plano ontologicamente pregnante, parece também apontar para uma crítica implícita aos atuais reducionismos de cunho somatizante. Mantém-se, no entanto, a ambiguidade do gesto, convocando no mínimo as seguintes indagações: trata-se de uma reciclagem de toda a tradição cultural sedimentada ao longo dos últimos séculos na literatura (e na psicanálise) em uma clave somatizante, ou seja, de um transplante da tradição da cultura letrada para esse novo horizonte de sentido? Ou estaria aí em jogo exatamente um abalo dessas novas crenças biopolíticas, por meio da forte reintrodução da tradição literária?

O horizonte de sentido em que o livro se instala - e é ele que nos interessa aqui -, especialmente no mundo anglo-saxão, certamente colabora para a manutenção dessa ambiguidade. Basta nos indagarmos, por exemplo, se nesse novo horizonte ontologicamente esvaziante, um Gregor Samsa (e todo Kafka, todo Beckett etc) seria possível. A patologização biopolítica em franca expansão cultural parece colocar em risco a produção e invenção de novas ontologias possíveis, de novos territórios existenciais a serem ficcionados, tendendo a empobrecer o horizonte do dizível e do experienciável.

Ainda assim, certa resistência ontológica contra a patologização da vida não deixa de estar presente, em sua já assinalada ambiguidade, nesses Distúrbios atmosféricos, de Rivka Galchen. O psiquiatra se pergunta, a certa altura, quem já não se teria deparado com comportamentos totalmente resistentes à interpretação, "moods [estados ou humores] irredutíveis à serotonina ou circunstância"? E acrescenta, em um verdadeiro achado: "ações Teflon, nas quais nenhuma teoria adere" (GALCHEN, 2008, p. 174).

Uma breve pesquisa na internet informa que o politetrafluoretileno, um polímero mundialmente conhecido pelo nome comercial de teflon, acidentalmente descoberto nos anos 30, foi registrado pela empresa americana DuPont e patenteado para fins comerciais em 1946. Quem de nós ainda não se lembra como era fritar um ovo sem o teflon, tendo de colocar na obsoleta 
frigideira muito óleo ou manteiga para não grudar, assistindo ao embate épico entre o orgânico e o inorgânco? E quem já não observou ovos fritos, sem atrito nem necessidade de mediação, em uma frigideira teflon magicamente deslizante e nada dramática? Material com o mais baixo coeficiente de atrito e maior grau de impermeabilidade, o inorgânico teflon expressa perfeitamente essas superfícies deslizantes em que o desacreditado verdadeiro ou real já não se deixa aderir, grudar ou mesmo apreender.

Para dar conta desse aspecto fugidio e imprevisível, o romance convoca dois modelos articuláveis entre si, um deles extraído da cultura letrada ocidental (literatura, filosofia, psicanálise), e outro, no interior da própria trama, referido a teorias e modelos de predição meteorológica. Embora não possamos aqui explorá-los na riqueza de seus detalhes, mencionemos alguns dos exemplos mobilizados no romance. Três autores e citações funcionam, de modo explícito, como possíveis alternativas à leitura redutora das distorções perceptivas sob a clave dominante do distúrbio mental: Adorno, Dante e T. S. Eliot. Essas referências sugerem, aliás, que a autora parece aderir a seus estudos humanísticos contra a pressão atmosférica da cultura somática e de sua própria especialização em psiquiatria. Sugere ainda que ela se serve de sua dupla formação para jogar a matriz letrada contra essa atmosfera cultural redutora (as neuroperspectivas), emprestando mais "profundidade" e restituindo textura ontológica aos modos de subjetivação teflon, chapados e sem espessura, que tendem a se expandir atualmente nas sociedades liberais avançadas.

Vale a pena relembrar, de saída, a referência a Adorno, menos previsível no contexto da trama. Eis a passsagem citada, tal como no romance: "A irrealidade das brincadeiras das crianças dá a ver que a realidade ainda não se tornou real. Inconscientemente, elas ensaiam a vida certa ("the right life")." (GALCHEN, 2008, p. 122). A referência a Eliot remonta, em duas passagens, ao último dos Quatro Quartetos. Eis a primeira delas: esbarrando no fantasma de Yeats, nas ruas bombardeadas de Londres, o poeta afirma que ambos eram "por demais estranhos um ao outro para qualquer desentendimento" (Idem, p. 150). Tal como enfatizado por Freud no tema do Umheimliche, só a familiaridade (não a total estranheza) e certa proximidade (não a distância) podem suscitar os próprios desentendimentos e estranhamentos. Mais adiante, outra vez Eliot: "Down the passage which we did not take/ Towards the door we never opened/ Into the rose-garden.../ But to what purpose.../ I do not know.../ Shall we follow?" (GALCHEN, 2008, p. 174). Reabre-se o tema da proliferação de mundos paralelos, inclusive entre vivos e mortos. Multiplicação leibniziana ao infinito de mundos possíveis, todos coexistentes, mas desprovida da firme mão divina garantidora de uma "harmonia pré-estabelecida" que só permitiria a realização 
de um único mundo, e - como se isso não bastasse - do melhor dos mundos possíveis.

O tema dos mundos coexistentes, paralelos, virtualmente intercomunicáveis (também entre vivos e mortos) ganha no romance uma versão high tech, cibernética. Afinal, como se ter certeza absoluta de quem de fato nos envia e-mails? Essa observação intervém porque Leo recebe, em seu blackberry, mensagens enviadas pelo meteorologista Gal-Chen, morto desde 1994. O próprio toque mágico que faz aparecer e extinguir-se a luz espectral desses novos dispositivos eletrônicos ${ }^{5}$ também reedita e atualiza o tema dos duplos e dos mundos possíveis. Como, por exemplo, quando Leo comenta que a tela, lugar de troca com o já falecido meteorologista, cai novamente em sono pesado, e o médico, com um breve e preciso toque, faz com que ela volte novamente à vida (Idem, p. 153). Trata-se de um gesto a que vamos nos acostumando, trazendo à luz ou deixando-se esvair espectros reais e luminescentes.

A terceira referência a ser destacada remete a Dante. Nela se propicia uma articulação dos temas reciclados - dos duplos, da mise en abîme dos simulacros, do Unheimliche, da coexistência real de mundos paralelos - ao modelo meteorológico de investigação das perturbações atmosféricas da terra e dos comportamentos. A alusão a Dante se refere a seu tratamento peculiar do modo de ser dos mortos: estes conheceriam o passado e até o futuro, mas nada acerca do presente (GALCHEN, 2008, p. 149). O tempo "presente", em sua variabilidade infinitesimal, fluir ininterrupto de um movimernto absoluto e indivisível (como nos ensinou Bergson) escaparia mesmo aos mortos, que se conhecem bem melhor do que os vivos. Viver é estar suspenso no presente, suspenso no tempo, com suas intempéries e variações atmosféricas (Idem, p. 149). No romance, os modelos meteorológicos propostos pelo Dr. Gal-Chen respondem a essa condição, introduzindo o randômico, distorções e erros a fim de propiciar previsões mais acertadas acerca do futuro.

Para dar conta desse campo fluido, em variação contínua e indeterminada, inevitavelmente aberto às forças do caos e do acaso, é preciso mobilizar conceitos porosos, aproximativos. É o caso de atmosfera: no vigor de sua sutileza, em seu caráter intrinsecamente aleatório, pouco afeito à rigidez cadavérica dos sistemas fechados, pode servir a um pensamento que, sem pretender recobrir o real (reencontar a verdadeira Rema perdida), nem por isso recairia na falácia e na aporia do mero deslizar em superfícies teflon. A atmosfera é algo de bastante palpável: por exemplo, se diz que reinava, em tal ambiente, certo clima ou atmosfera pesada, leve, densa etc. Associa-se à concepção bergsoniana da realidade, que contém grandes parcelas de virtualidade. O clima ou atmosfera é tão avesso ao fechamento das definições quanto acessível à percepção imediata. 
A partir dessa noção porosa (na linhagem de outras noções, como as de "graça" ou "charme"), Hubert Damisch explora a "atmosfera" em sua Teoria das nuvens na pintura, e José Gil dela também se vale para dar conta da produção real de atmosferas entre os corpos na dança contemporânea, introduzindo o risco de surtos psicóticos (por contágios e contaminações entre inconscientes), deflagradora igualmente do inconsciente das próprias coisas.

As atmosferas, suas forças, pressões e distúrbios estão fortemente presentes no pensamento de Nietzsche, de modo ainda mais explícito a partir do início da década de 1880, quando o filósofo, voltando-se contra o "idealismo", dedica sua pouca acuidade visual a leituras de obras de meteorologia. Nietzsche estabelece então conexões diretas entre seu estado de corpo, sua saúde e o elemento elétrico, instável e incontrolável das variações atmosféricas. Decepcionado com o caráter rudimentar da "meteorologia médica", eis o que ele escreve a Franz Overbeck em 28 de outubro de 1881:

Talvez já se saiba mais agora - eu deveria ter estado na Exposição de Eletricidade em Paris, em parte para aprender o que há de mais novo, em parte como objeto da exposição: pois como pressentidor das alterações elétricas e como o que se chama de Profeta do Tempo, sou como os macacos e, ao que parece, uma 'especialidade'. Hagenbach pode por acaso dizer com que roupa (ou correntes, aneis etc) se pode proteger melhor contra essas influências fortes demais? (cf. FERRAZ, 1994/2009, p. 114-115).

Com seu corpo elétrico (tal como aquele cantado por Walt Whitman), como antena atmosférica e barômetro hipersensível, Nietzsche efetuou-se como profeta do tempo, em seu duplo sentido. Também no romance de Rivka Galchen o psiquiatra retoma, ainda que de modo derrisório, a velha questão da diferença entre loucos e profetas. Segundo Dr. Leo, a diferença residiria no fato de que, enquanto o louco projeta e escreve um mundo que lá não está, o profeta, em seus delírios, consegue ler seus movimentos efetivos, mesmo que invisíveis para um olhar trivial. Nesse sentido, suas alucinações podem estar dizendo algo acerca do que é, mesmo em estado virtual (na precisa definição bergsoniana, real, sem ser atual), em movimentos infinitesimais e pouco perceptíveis para uma "atenção à vida" pragmaticamente orientada. Como mostrou Bergson, essa "atenção à vida" empresta familiaridade ao sempre cambiante, imobilizando e compartimentando o fluxo a fim de poder agir no mundo. No caso do Dr. Leo, entretanto, essa possibilidade profética se encontra sobredeterminada, portanto esvaziada, pela interpretação de cunho somático, patológico. Sua profecia do tempo não passará de puro delírio, uma vez que ele incorpora no sentido mais literal a interpretação neurológica, concluindo o périplo e seu fracasso ontológico com a reafirmação de sua doença. 
Ainda assim, em sua viagem delirante pelo extremo sul da América Latina, Leo Liebenstein também percebe, por momentos, o rumor distante de glaciares em vertiginosa queda, expressando sua perda de balizas e coordenadas, seus distúrbios atmosféricos somaticamente determinados, mas sugerindo igualmente a verdadeira guerra entre versões sobre mudanças climáticas que se entrecruzam no presente na atmosfera da terra. Deve-se tão-somente diagnosticar sua síndrome, ou ouvir o que seu corpo também pressente, movimentos reais do planeta? A interpretação neurológica, inscrita no horizonte de sentido tendencialmente dominante na cultura anglo-saxônica atual, inviabiliza essa suspeita e possibilidade, tornando-a obsoleta. Essa perspectiva erige suas novas narrativas mitológicas - que, obviamente, não se apresentam como tais - por sobre o legado da velha cultura letrada.

Atmosferas em constante alteração parecem convocar metodologias e conceitos aptos a acolherem as forças caóticas do fora. No romance, emerge sob o modo de um modelo diagramático reproduzido a partir de um artigo (real?) do meteorologista Tzvi Gal-Chen. Eis o desenho de suas linhas abstratas de força (GALCHEN, 2008, p. 58):

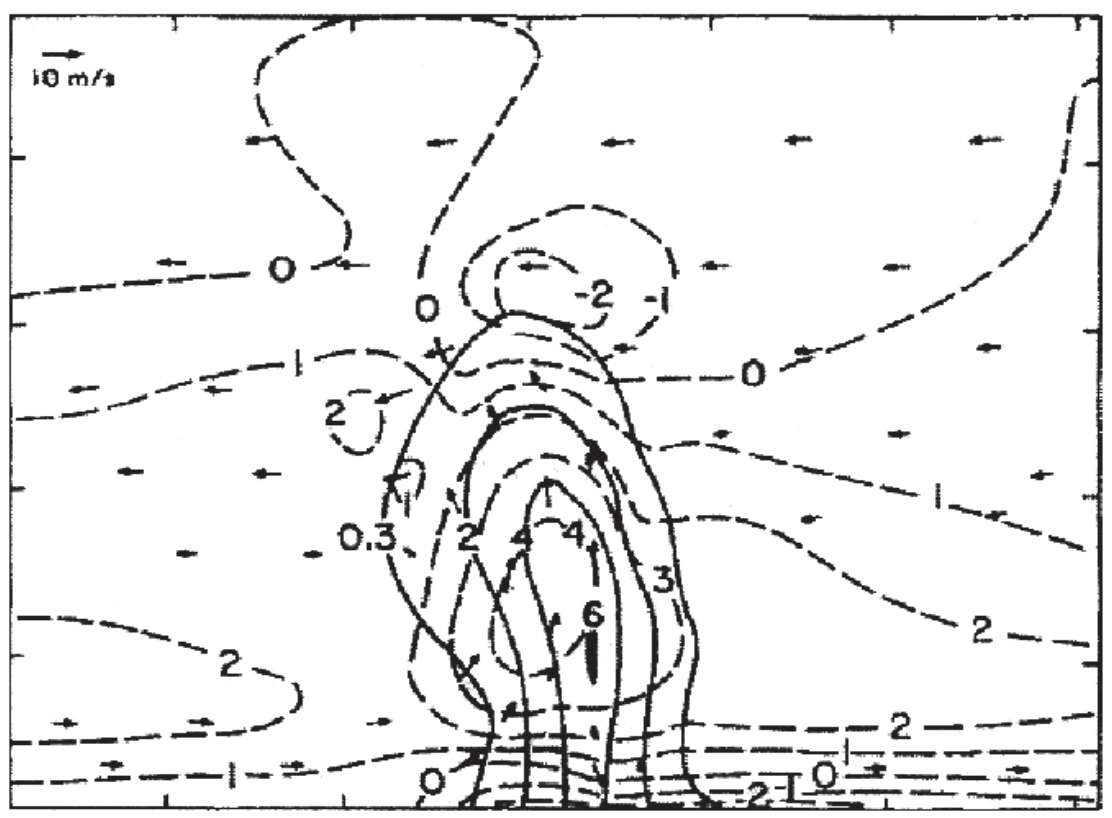

Figura 1: Linhas abstratas de força

Esse diagrama oscilante e sinuoso também é lido pelo personagem como "a imagem de um homem partindo relutantemente": "Não é um retrato de mim, deixando primeiro meu apartamento, depois o conforto da casa de infância de Rema, a fim de realizar minha triste e incerta pesquisa? Que estranha essa semelhança." (GALCHEN, 2008, p. 162). Entretanto, 
insinua-se também aqui uma derradeira ponta de ambiguidade: serviria esse diagrama à empreitada ontológica, ou se trata de mais uma cínica e perversa apropriação da potência ontológica do pensamento contemporâneo, em função do enquadramento neurológico a que adere o romance de Galchen?

Qualquer que seja o desenlace dessa questão, o que nos interessa ressaltar é a corrosão do ontológico que parece estar em curso, alavancada por reduções neurológicas da experiência humana, contribuindo para a produção e perpetuação de narrativas e vidas teflon. A menos que, em seus distúrbios atmosféricos, o próprio psiquiatra destronado venha a se transformar - mesmo que de um modo oblíquo, ou lido em uma perspectiva enviesada - em um profeta do seu, do nosso tempo.

\begin{abstract}
This article exploits some aspects of the so-called contemporary "somatic" culture as expressed in recent anglo-saxon novels. It analyses the novel Atmospheric Disturbances, written by Rivka Galchen and published in 2008. The increasing cultural and midiatic emphasis on the materiality of the body - specially on the brain, on hormones and genes - tends to be applied to all human experiences, enhancing scripts of subjectivation biologically based. New syndromes described and labeled in a proliferating way medicalize and domesticate ambiguities and weardnesses which have been elaborated for centuries, in different ways, by the Western literate tradition (from literature to psychoanalysis). The critical reading of Galchen's novel opens up certain crucial ethical, political and philosophical questions implicated in the ongoing process of naturalization, closely related to a progressive despiritualization of the human phenomenum.
\end{abstract}

Keywords: somatic culture; anglo-saxon literature; contemporary subjectivity.

\title{
REFERÊNCIAS
}

AGAMBEN, Giorgio. O poder soberano e a vida nua - Homo Sacer. Lisboa: Editorial Presença, 1998.

BERGSON, Henri. Mémoire et vie (textes choisis). Paris: PUF, 1975. DAMISCH, Hubert. Théorie du nuage (pour une histoire de la peinture). Paris: Seuil, 1972. 
FERRAZ, Maria Cristina F. Nietzsche, o bufão dos deuses. Rio de Janeiro: Relume Dumará, 1994/ Ediouro-Sinergia, 2009.

GIL, José. Movimento total - o corpo e a dança. Lisboa: Relógio D'Água, 2001.

GALCHEN, Rivka. Atmospheric Disturbances. Londres: Harper Perennial, 2008.

ROSE, Nikolas. The Politics of Life Itself. Princeton e Oxford: Princeton University Press, 2007.

ROTH, Marco. 2009. "The Rise of the Neuronovel." N+1, issue 8,19 October.

www.nplusonemag.com/rise-neuronovel

ZIZEK, Slavoj. Bem-vindo ao deserto do real! São Paulo: Boitempo Editorial, 2003. 